Publisher policy allows this work to be made available in this repository. Published in Journal of Documentation by Emerald. The original publication is available at: https://doi.org/10.1108/jd-05-2015-0060. Buchanan S \& Tuckerman $L$ (2016) The information behaviours of disadvantaged and disengaged adolescents. Journal of Documentation, 72 (3), pp. 527-548.

\title{
The Information Behaviours of Disadvantaged and Disengaged Adolescents
}

\begin{abstract}
Purpose: The purpose of this paper is to evidence and better understand adolescent information behaviours in disadvantaged and disengaged circumstances, and explore issues of social integration.

Design/methodology: interdisciplinary theoretical framework bringing together theories of information behaviour with theories of social capital. Mixed method design incorporating observation, interviews, and focus group conducted in areas of multiple deprivations. Participants' young people aged 16-19 not in education, employment or training (NEET); and their support workers.
\end{abstract}

Findings: Heightened access and internalised behavioural barriers found beyond those common to the general adolescent population, the former influenced by technology and literacy issues, the latter by social structures and norms. There is evidence suggestive of deception, risk-taking, secrecy, and situational relevance in information behaviors, and a reliance on bonding social capital characteristically exclusive and inward facing. Low levels of literacy and self-efficacy are significant interrelated issues, with NEET youth dependent upon support workers when seeking and processing information, and demonstrating passive non-motivated information behaviours often abandoned.

Research limitations/implications: Highlights the need for further interdisciplinary research to explore complex relations between social and affective factors, and that seeks to both understand and influence information behaviours in disadvantaged and disengaged circumstances.

Practical implications: Remedial literacy education recommended as an immediate priority for public and third sector agencies.

Originality/value: First study of adolescent information behaviours in disadvantaged and disengaged circumstances. Novel interdisciplinary theoretical framework evidences and draws attention to understudied and enduring information poverty issues of significant societal concern, potentially consigning a significant proportion of the youth population to a stratified existence within an impoverished (small) information world. Sets a focused interdisciplinary research agenda.

Keywords: information behavior; information poverty; information literacy; social capital.

Article classification: research paper

\section{Introduction}

We have limited understanding of adolescent information behaviours in disadvantaged (i.e. socioeconomic) and disengaged (i.e. education and employment) circumstances, yet 954,000 young people in the UK are currently not in education, employment or training (NEET), and at high risk of social exclusion (Miller et al, 2015; Wanberg, 2012; Kieselbach 2003). This study provides empirical evidence to support our hypothesis that heightened access and internalised behavioural barriers (beyond or not common to the general adolescent population) are consigning many young people to a stratified existence within an impoverished (small) information world; contributes to our understanding of information poverty; draws attention to a societal issue; and informs public and third sector intervention strategies.

Our overarching theoretical framework brings together theories of information poverty with theories of social capital to better understand information behaviours in impoverished circumstances and explore issues of social integration (understood as participation, access, and engagement). The study investigates NEET youth (aged 16-19) engagement with public and third sector support services during information seeking for education and employment purposes, and the extent of information poverty manifest.

\section{Background}

954,000 young people aged $16-24$ in the UK (13.1\% of all young people) are NEET (UK Office for National Statistics, 2014). Broken down further, 450,000 (47\%) are actively seeking and available for 
work and further classified as 'unemployed', while 504,000 (53\%) are not and further classified as 'economically inactive'; and while rates for young people classified as NEET and 'unemployed' have dropped from the previous year $(-25.1 \%$ (partly attributed to a UK raising of the mandatory participation age in education or training)), rates for young people classified as NEET and 'economically inactive' have risen $(+1.6 \%)$. A gender imbalance is also notable with women representing $37.2 \%$ of NEET youth 'unemployed' and $67.6 \%$ of NEET youth 'economically inactive'. A persistent deprivation gradient is also evident, with deprived regions of the UK having up to seven times the rate of NEET youth as those of least deprived regions, and $38 \%$ of all NEET youth living in unemployed UK households (Office of National Statistics, 2014; Audit Commission, 2010).

Similar statistics and trends are reported worldwide, including persistent or rising NEET rates (16-24 (general trend)) across the majority of OECD countries, with rates particularly high in emerging economies such as India, Saudi Arabia and South Africa (International Labour Organisation, 2014; OECD, 2014a). The global youth unemployment rate is three times higher than the unemployment rate for adults and is forecast to remain unchanged through 2018 (International Labour Organisation, 2015). For example, while the total unemployment rate in the US is $5.7 \%$, the rate for unemployed youth (16-19) is $18.7 \%$ (United States Department of Labor, 2014). In OECD league tables of NEET rates (OECD, 2014a), the USA is ranked $10^{\text {th }}$ highest and the UK $13^{\text {th }}$ highest out of 37 comparison countries, with both the USA and UK having rates above the OECD average. At high risk of requiring long-term state support (NEET status being a strong predictor of chronic unemployment (International Labour Organisation, 2014; Franzèn \& Kassman, 2005); in Scotland alone (the study zone), the cost of a single cohort of young people failing to transition into regular employment is estimated to be $£ 2$ billion (SPICe, 2012).

Disadvantaged and disengaged, and unlikely to reengage without interventions (particularly those deemed 'economically inactive' (Office of National Statistics, 2014; Audit Commission, 2010)), key factors contributing to sustained NEET status (6 months+) include: economic hardship, poor social functioning, teenage pregnancy/parenthood, delinquency, low educational attainment, substance abuse, disability, carer responsibilities, and lack of parental support (O'Dea et al, 2014; Welsh Government Social Research, 2013; Dietrich, 2012; Audit Commission, 2010; Kieselbach, 2003). Low self-esteem is a significant issue, as is stigma, both contributing to social exclusion and negative behaviours (Miller et al, 2015; Yates \& Payne, 2006; Kieselback, 2003). Miller et al (2015) reports that many NEET youth feel marginalized and perceive themselves to be viewed negatively by formal and traditional structures (civic and community), and that "this affected the young people's belief in equal opportunities and resulted in the development of varying resilience strategies, the most typical being isolation from and resentment to these structures" $(2015, \mathrm{p} 6)$. Delinquency rates are higher than peers, as is the prevalence of mental health issues (O'Dea et al, 2014; Audit Commision, 2010). The 2014 Princes Trust Annual Youth Index (Princes Trust, 2014), the largest UK youth study of its kind (2161 participants aged 16-25 (265 NEET)), reports that NEET youth are more than twice as likely as their peers to be prescribed anti-depressants, with $40 \%$ (n265) having experienced symptoms of mental illness as a direct result of their situation. Such issues are compounded by fatalistic opinions (Miller et al, 2015) and feelings of helplessness. The Princes Trust (2014) reports that $74 \%$ of NEETs stated that they would not ask for help even when struggling to cope, and that $72 \%$ felt that they had no one to confide in regardless.

State and third sector (single and multi-agency) interventions focus on personal support and development, skills development, work programmes and apprentiships. Information plays a core role: informing, guiding, and empowering; however while information behavior studies of NEET youth are non-existent (discussed below), related issues are reported within the public and third sector, most notably recent reports from the Organisation for Economic Cooperation and Development (OECD) and the UK Princes Trust. The OECD, in a review of employment factors and trends, report that, "weak information-processing skills among youth are more strongly associated with the probability of being NEET than educational attainment" (OECD, 2014b, p217), and highlight the risk of chronic unemployment without remedial training and support (but without prescriptive guidance). The Princes Trust (2013) report that NEET youth are significantly less likely to carry out job-related tasks on a computer than their peers due to a lack of skills and confidence, and that many are 'embarrassed by their lack of computer skills'. The Princes Trust report that $35 \%$ (n265) rarely or never look for jobs online, that $24 \%$ 'dread filling in online job applications', that $17 \%$ would not apply for jobs requiring basic computer skills, that $10 \%$ cannot send a CV online, and that $11 \%$ avoid using computers entirely. Perhaps unsurprisingly given above, Lanning \& Rudiger (2012, p14) report that 
NEETs "often struggle to navigate the policy environment and support available to them" with a "better and more coordinated transition system" recommended, that "would include good information, advice and guidance to help young people navigate the choices available".

A challenge in responding to such issues relates to our limited understanding of adolescent information behaviours in disadvantaged and disengaged circumstances, which might inform tailored solutions and interventions. Empirical studies of the information seeking behaviors of NEET youth are non-existent, and arguably limited in circumstances that could be characterised as disadvantaged and/or disengaged. For example, while Agosto \& Hughes-Hassell (2006a; 2006b) investigated the everyday life information needs of adolescents from a 'lower socioeconomic division', participants were all high school students and variously members of extra-curricular leadership and after-school programs; and while Webber and Zhu (2007) and Julien (1999) investigated employment related information needs of adolescents, participants were again students (and majority part-time employed). Overall, students have been the predominant (if not sole) participants in studies of adolescent information behaviors; however, insight can nonetheless be gained from general population adolescent studies.

Ofcom (2014a; 2014b) report that young people (age 16-24) are increasingly cross-media multiscreening and multitasking on a day-to-day basis from a variety of locations; and spend approximately 24.2 hours per week online, with general browsing and sending/receiving emails the most regularly undertaken activites, followed by looking at social networking sites/apps, online purchases, using instant messaging services, and online banking and bill payment, followed by finding information for work/job/studies, looking at news websites or apps, and finding information for leisure time (see Ofcom $2014 \mathrm{~b}$ for the full list encompassing less frequent activities).

Agosto et al (2012) report that adolescent (age18) choice of personal communication media (social media and other ICT) is based on social context, closeness of relationships with receivers, and number of receivers. Five independent variables are identified (relationship factors; information/communication factors; social factors; system factors; self-protection factors), and one moderating variable (recipient factors). Text messaging is used most frequently to communicate quickly with close friends, and to a lesser degree, family. Social networks are used to communicate with a wider range of friends and to post images, update statuses etc. Email is the preferred medium to communicate with authority figures as it is considered more formal and less personal. Deeper information exchanges are conducted face-to-face or via voice call, smaller information exchanges and/or urgent information needs via text or social network, and less urgent information needs via email. Voice calls are made infrequently, often when more intimate face-to-face communication is desirable but not possible.

Agosto and Hughes-Hassell (2006a) report that the everyday life information needs of adolescents (14-17) are commonly of a personal developmental nature, and relate information needs to seven (independent, overlapping and variable) areas of adolescent development: social self; emotional self; reflective self; physical self; creative self; cognitive self; and sexual self. Agosto and Hughes-Hassell (2006b; 2005) report friends and family to be the preferred information sources and a preference for online sources over print resources.

Foss et al (2013) identify seven online search roles (patterns of online search behavior) found in adolescents (aged 14-17): power; developing; domain-specific; non-motivated; rule-bound; visual; and social. When compared to a previous study of children (ages 7, 9, 11), Foss et al (2013) found that: search skills increase with adolescence (fewer developing and domain-specific searchers, and more power, rule-bound and visual searchers); and searches for social purposes increase with adolescence, as does the influence of friends on search and computer use. Foss et al (2013) also found, in comparison to children, that none of the adolescents exhibited distracted search behavior (attributed to increased focus associated with increased maturity and experience), and reported a lower number of non-motivated searchers. Foss et al (2013) also found that while adolescents reported friends as having a significant influence on search and computer use, none of the participants categorised as 'non-motivated' reported this, and suggests potential relationships between social influence and search motivation for further exploration. 
Studies by Julien (1999) and Whebber and Zhu (2007) provide insight into information behaviours of adolescents in the education and employment context. Julien $(1999$, p47) reports that 'many adolescents did not understand what decisions they needed to make about their futures' and that 'this lack of clarity led many adolescents to feel anxious and overwhelmed' during employment related information seeking and decision making. Julien (1999) also found that 40\% (n400) of adolescents did not know were to go for assistance, that $38 \%$ felt that they needed to go to too many different places for information, and that $23.4 \%$ lacked confidence to ask for information. Notably, Julien (1999) found a proportionally higher number of respondents of low socioeconomic status lacked confidence, and highlights the negative impact of low confidence on self-efficacy. Webber and Zhu (2007) examined the employment related needs of Chinese young people (18-26) and report 55\% (n78) experiencing barriers when seeking information (although the nature of the barriers are not identified\}, and highlighted the Internet as an increasingly important source of information beginning to bypass traditional channels such as print media (although Williamson et al (2012) reports traditional print media as still considered an important and convenient news source by adolescents, often influenced by parents media choice and habits).

We also know that the Internet can be an important source of health information for adolescents, with information found online reported to influence subsequent behavior (e.g. Rideout, 2002); however Kim \& Syn (2014) report low health literacy levels amongst adolescents and that they, "have difficulty locating and understanding the basic health information needed to solve issues and make informed decisions" $(2014$, p5). Issues of provision are also reported, with a study by Bowler et al (2011) investigating the visibility of public health portals for adolescents, and in particular, which websites refer adolescents to reliable health information, finding a low level of tailored provision and visibility, and reporting that 'teens health information needs are being met by sources that lack expertise in health care' (2011, p443).

While adolescents have been found to be able to complete more complex search tasks than children (e.g. Foss et al, 2013), literacy issues are nonetheless reported. Bowler (2010, p1333) reports that, "adolescents, although technologically adept, still find information seeking to be a difficult task" and, supporting a 30-year study by Rowlands et al (2008), concludes that "their information search skills have not improved over time". There is evidence that adolescents have a tendency to overestimate their search skills (e.g. Ofcom, 2014b; Bowler, 2010; Pickard, 2004; Jackson \& Banwell, 2005; Chung \& Neuman, 2007), and ability to assess the credibility of information (e.g. Ofcom 2014c; Harris, 2008); and have a tendency to simplify tasks and effort expended (e.g. Nicholas et al, 2011; Shenton \& Dixon, 2004). There is also evidence suggestive of a generational divide, with 62\% (n1660) of parents considering their children (aged 12-15) to know more about the Internet than they do (Ofcom, 2014c). Sanchez-Navarro \& Aranda (2013) report 54\% (n2054) of 12-18s have learnt to use the Internet themselves; while a study by Foss et al (2013, p.181) reports that "while school becomes more of a motivating factor to search for children as they age into adolescence, classroom search education is not keeping pace". In such circumstances public libraries (PL) can provide a key information access and support role, but we also know that the use of PL declines dramatically with adolescence, attributed to a disconnect between service provision and service demand (The Reading Agency, 2011, The Reading Agency, 2004), and negative views of libraries and librarians (Agosto and Hughes-Hassell, 2005; Julien, 1999). In relation, recreational reading, which is reported to enhance academic performance, social engagement, and personal development, also declines throughout adolescence (Howard, 2011).

It is important to acknowledge that adolescents are not homogenous (nor NEET youth (Stoten, 2014)), but the above studies nonetheless provide evidence of a number of access and behavioural barriers. There will of course be many adolescents unaffected by such barriers, and others to marginal degrees; but it is also reasonable to hypothesise that barriers will be heightened in disadvantaged and disengaged circumstances. What we lack is empirical evidence. Consequently, this study asks two key research questions: do disadvantaged and disengaged youth face heightened barriers to information access and use beyond or not common to the general adolescent population; and has this consigned them to an impoverished (small) information world?

\section{Methodology}

This study sought to better understand adolescent information behaviours in disadvantaged and disengaged circumstances, and issues of social integration; by investigating NEET youth engagement 
with public and third sector support services during information seeking for education and employment purposes.

\section{Theoretical framework}

Our theoretical framework brought together theories of information poverty with theories of social capital to better understand issues of human information behavior and social integration.

Chatman's (1996) research into the (small) information worlds of outsiders, and associated theoretical framework for describing an impoverished information state, was identified as of particular relevance to this investigation given perceptions of marginalization and helplessness reported amongst NEET youth (e.g. Miller et al, 2015; Princes Trust, 2014; Yates \& Payne, 2006). Chatman (1996) draws on insider/outsider theories from the social sciences (i.e. Merton, 1972) to explore how insider/outsider identify influences information behaviours, noting that "Based on previous research, one can make a prima facie case that people who live in an arduous social landscape view outsiders with selfprotective eyes" (1996, p205). Chatman (1996) provides a theoretical framework for exploring information poverty (for further discussion of conceptions of information poverty in library and information science, see Haider \& Bawden, 2007), based on four core concepts that define the basis of an impoverished information world: deception (distortion of the truth), risk-taking (aversion to risk), secrecy (intentional concealment), and situational relevance (immediate utility); and six propositional statements, that describe an impoverished information state as one in which people (to various degrees) perceive themselves to be devoid of sources of help, are influenced by outsiders who withhold privileged access to information, adopt self-protective behaviours in response to social norms, are mistrustful of the ability of others to provide useful information, withhold their true problems in the belief that negative consequences outweigh benefits, and selectively receive new information in response to their everyday needs (including a failure to see external information sources as of direct and immediate value to lived experiences). Chatman reports that in impoverished circumstances (though not exclusively, see for example: Brittz, 2004; Lingel \& Boyd, 2013) a stratification of information access and use will be evident, with information needs and sources localized, and outside sources not usually sought for information and advice in a "world on which [social] norms and mores define what is important and what is not" (1996, p205). Such concepts and issues also drew our attention to the applicability of social capital theory.

Widely recognised as a strong predictor of individual health and wellbeing, social capital refers to "features of social life - networks, norms and trust - that enable participants to act together more effectively to pursue shared objectives" (Putnam, 2000, p2). Recognising that "social capital can operate through the diffusion of information" (Drentea \& Moren-Cross, 2005, p924) and that public and third sector agencies such as PLs "can contribute to the building of social capital by promoting the types of interaction and integration which enable social networking and by providing citizenship information resources" (Goulding, 2004, p4); a particular strength of incorporating a social capital perspective (for our purposes) is that it "shifts the focus of analysis from behaviour of individual agents to the pattern of relations between agents, social units and institutions" (Schuller et al., 2000, p35). We are particularly interested in issues of social integration, understood as participation, access, and engagement, which will assist with exploring Chatman's (1996) insider/outsider theories associated with both information poverty and the sociology of knowledge. These concepts will be progressed by investigating the role and influence of social networks during information seeking, the various networks and strategies (i.e. bonding (close, immediate peer and family connections), bridging (more distant connections with people of similar demographic characteristics), and linking (institutional connections via people in power positions)) used to more broadly engage with individuals and service providers, and importantly, the factors influencing interactions.

\section{Methodological design}

A key consideration was how best to approach vulnerable subjects in disadvantaged and disengaged circumstances. A pragmatic route is via support groups, with this study undertaken with the cooperation of three public agencies providing drop-in support services (employment and training) to NEET youth in South Ayrshire: Skills Development Scotland (SDS), South Ayrshire Councils Skills Towards Employment (STEP), and Access to Employment (AtE). However, while facilitating trust, this route does not in itself guarantee automatic acceptance (O'Dea et al, 2014; Yates \& Payne, 2006; Hammer, 2003). Our approach would therefore need to incorporate time to establish a degree of 
familiarity between researcher and subject conducive to acceptance and participation, and be sensitive to issues of low self-esteem and confidence. Ethical approval was obtained via Institutional Ethics Committee, with all experiments run in strict accordance with the guidelines set out by the University of Strathclyde Code of Practice on Investigations of Human Beings.

Taking the above into account, observation and semi-structured interviews supported by a focus group were selected as the data collection methods. Observation (observer-as-participant (Bryman, 2012)) over a period of four weeks prior to interviews provided the researcher with a degree of immersion in the research environment (drop-in support groups), reducing researcher influence and induced observee reaction, and importantly, decreasing the impact of the researcher's presence (Pickard, 2007); and allowing a degree of trust and acceptance to be established (recognized as particularly important with young people (Gentry \& Campbell, 2002)). Information behaviors, social interactions and experiences were observed, with note taking conducted sparingly to maintain a sense of normality (Pickard, 2007)).

To further investigate information behaviours, semi-structured interviews followed observation; to gain a degree of cognitive insight and understanding of attitudes and motivations, and their influence on information behaviours and social interactions. Participants were asked to identify and describe important (critical incident) everyday information needs, including where they went to obtain information, and any difficulties experienced. Critical incident technique focused discussion on important real life scenarios and needs, and encouraged participants to describe actual activities undertaken (Johnson, 2004). It was not our intention to develop typologies of information needs and sources, but identifying them helped provide narrative structure to discussions that sought to explore interactions, attitudes and motivations. Two pilot interviews highlighted the importance of having a semi-structured format and examples to prompt discussions (pilot volunteers requiring prompts to encourage discussion). Interviews took place within the familiar surroundings of the support group, and were not recorded to maintain an informal atmosphere (and notes taken sparingly during interviews and written up post-interview).

Post interviews a focus group was conducted with volunteers from the previous individual interviews, who were asked to review and/or add to collated information sources identified from the interviews, and to place them on a matrix according to perceived credibility and frequency of use, and to discuss/explain placements as they did so (with minimum researcher (as moderator) intervention). The focus group allowed us to explore how individuals discussed information behaviours as a group versus as individuals (i.e. providing insight into group interactions and opinions). The matrix exercise was introduced for participatory purposes, with the true purpose the discussion around. Cognisant to interpretation issues associated with 'technical' language, at the outset terms were carefully described to participants using various additional descriptive terms such as 'accurate' and 'correct' for credibility, and 'use' and 'how regularly' for frequency.

To gain support worker insight into NEET youth information behaviours, individual interviews were also conducted with support workers. These were conducted post NEET youth interviews (and focus group) and followed a similar semi-structured format exploring information needs (of NEET youth) that support workers dealt with on a day-to-day basis, source preferences, and barriers observed.

Data analysis (reduction, display, conclusions and verification) was approached deductively, and conducted recursively in parallel to and post collection. Thematic analysis followed Braun and Clarke's (2006) approach: data transcription and familiarisation; initial code generation; collating codes into themes; reviewing themes; refining themes; and producing themes. Data was disaggregated into meaningful categories via identification of patterns and regularities through a process of iterative pattern coding (Miles and Huberman, 1994). Initial 'start-lists' were based on (but not limited to) Chatman's (1996) concepts of information poverty (e.g. deception, risk-taking, secrecy, situational relevance), and concepts of social capital (e.g. bonding, bridging, linking (Putman, 2000; Woolcock, 2000)). Periodic check-coding of field notes and margin coded transcripts was conducted to validate developing code structures. Identified themes were cross-checked for coherence, consistence and distinctiveness (Braun and Clarke, 2006). Narrative analysis (of interview transcripts) was conducted to provide temporal sequence and context to information behaviours, and shift attention from "what happened" to "how people make sense of what happened" including their sense of place and sense of role within recalled events (Bryman, 2012, p582); facilitating examination 
of aspects of social networks and integration, and engagement factors. Findings were cross-checked and verified via triangulation.

\section{Sample}

A purposive approach to participant sampling defined the key adolescent inclusion criteria as being age 16 to 20 and NEET status; and the support worker inclusion criteria as being a public agency support worker directly engaged in providing employment and training support. Number of NEET youth observed would be out-with our control given the drop-in nature of support groups, but for interviews, we sought a minimum of six participants and a maximum of twelve, recognising that in purposive samples, six interviews can be "sufficient to develop meaningful theories and useful interpretations" (Guest at al., 2006, p78), and that saturation can be reached after twelve interviews (Guest et al., 2006). For the focus group we sought four to six participants, again in line with recommendations and common practice (Bryman, 2012).

The study zone, South Ayrshire, was identified via the Scottish Index of Multiple Deprivation (SIMD, 2012) as having a number of areas of multiple deprivation, with $17.7 \%$ of South Ayrshire datazones within the $20 \%$ most deprived decile, including several zones within the main town of Ayr within the $5 \%$ most deprived decile.

\section{Findings}

In total, thirty-six NEET youth were observed attending drop-in sessions at three separate locations in South Ayrshire (Ayr, Girvan, Maybole) over a period of four weeks. Post-observation fifteen NEET youth were interviewed (opportunistic extension), and four took part in a focus group. Six support workers were also interviewed.

\section{Observation}

Facilitated by community support workers and lasting approximately two hours, drop-in sessions are primarily intended to focus on assisting young people with employment and education related decisions and planning; however in practice, support was observed to be much more wide-ranging.

Many young people arrived in small groups of two to three and began job searches and/or applications together. Young people often began online job searches with the UK Department for Work and Pensions Universal Jobmatch service. Other websites commonly observed in use were MyJobScotland, Gumtree, and Monster. In relation, many were observed having problems remembering online sign in details, and completing online applications, often requiring assistance and/or motivation from support workers to do so. For example, one young person, referred via their Job Centre and with their benefits currently sanctioned due to a sustained period of inactive job searching, was observed attempting to set up a new universal job match account because he had forgotten his account number and password, altering his name and creating a new email address in the process. He then advised support workers that he could not make an appointment with another agency because he did not have a phone. The support worker then telephoned to make an appointment on his behalf, before discovering that he already had an appointment.

Abandonment and incompletion were common occurrences, often irrespective of support worker efforts. For example, two young people accompanying each other and both applying for modern apprenticeships could not remember their respective qualifications, which the support worker had to look up for them (support workers later commented this was a common occurrence). One then had to create an email address, but after doing so deemed the application process too complicated and left with her companion with neither having completed their respective applications. Another young person was observed struggling with the content of a cover e-mail for an application. A support worker asked him how he was getting on and he indicated that he needed assistance. The support worker reminded him that she had made cover e-mails for him before and that they were in his e-mail account; however, she created another one for him. Later on another support worker was observed conducting online job searches for him and suggesting opportunities he might consider applying for, but without observable response or action from the young person, who left shortly after. 
Young people were repeatedly observed requesting information from support workers regarding preparation for interviews (jobs and placements), appearing unsure as to what was expected of them and how they should conduct themselves. Financial information needs and problems were also observed. For example, one young person needed to open a bank account to receive their educational maintenance allowance, and was observed making arrangements for a support worker to accompany her to the Bank to do so. Another young person had difficulties understanding information about her personal finances. She stated that she had a sum of money that could be part of her benefits or have been deposited by her father, the support worker then helping her understand her bank statement. Another appeared confused over changes to her benefits (again, support workers later commenting that this was a common occurrence), again receiving assistance from a support worker to understand.

Personal circumstances, several of a sensitive nature, also arose during support worker interactions with young people. For example, one young person estranged from her own family and who had recently relocated to live with her partner and his parents, all of whom were unemployed, discussed being extremely unhappy with her new home life with support workers. The support workers talked to her about her options if she moved out, advising her of charities such as Seascape which could help her with deposits for private rental housing, and of the local council housing waiting list and how to apply. The support workers, who later commented that they were concerned about isolation and lack of social support, were also observed suggesting local girls groups and volunteering groups that she might join.

Many young people appeared visibly withdrawn, and were reluctant or unable to engage in discussion with support workers. For example, a support worker was observed asking one young person what type of employment she was interested in, and receiving no answer. The support worker then suggested that she think about people she knows (citing family, friends, or television characters/personalities) and if any of them have a career that she might be interested in, and also suggested example areas of employment in the local area (admin, childcare, retail, catering, hospitality etc.). In delayed response the young person identified what she did not want to do, but appeared unable to express what she would like to do, with the conversation petering out. At other times, responses to support worker efforts to engage with young people could be unexpected or erratic. For example, one young person who was yet to engage in activities or discussions, and had placed themselves peripheral to activity, was approached by a support worker and asked how she was and what she had been doing. The young person replied in a sullen manner that she had fallen out of a car at the weekend while intoxicated, before once more falling silent. The support worker later commented that the young person had confidence and literacy issues.

Young people were also repeatedly observed passively receiving (local area) travel information from support workers to get to and from interviews and other agency appointments, extending to associated recreational pursuits offered as part of community engagement projects. For example, at one session three young people were going mountain biking the next day, for which they had to get to Ayr. One support worker told them when they must arrive in Ayr and asked if they knew which bus they needed to get; none answered, so the support worker checked the times and advised them which bus to get.

At one session a nurse practitioner brought an educational game for the young people to play. The game had cards that addressed various health issues faced by young people (sexually transmitted diseases, drugs and alcohol misuse etc.). The nurse asked young people to look at the cards (left out on desks around the room) and told them that they did not have to play if they did not want to. The vast majority did not play with one voluntarily stating that he could not play because he could not read. Engagement of others was brief and appeared largely cursory.

Interviews: young people

In total, 15 young people were interviewed aged between 16 and 19: five 16 year olds, five 17 year olds, one 18 year old, and four 19 year olds (avg. participant age 17.3). Ten (67\%) participants were female, five (33\%) male. Ten (67\%) had left school after their fourth year without attending Further Education (FE). Two (13\%) had left school after fourth year and gone on to complete FE courses (one an Intermediate 2 and the other a SVQ3). One (7\%) had begun but not completed fifth year at school. 
One $(7 \%)$ had completed sixth year and then gone on to start but not complete a FE course. One (7\%) participant declined to disclose education details.

Five participants (33\%) spent approximately 1-3 hours online per day, three (20\%) 3-6 hours, and six $(40 \%) 6+$ hours, the most popular activities cited being general browsing, social networking, and music and gaming. Five (33\%) conducted job searches online. When asked how they usually accessed the Internet, seven (47\%) participants used their mobile phone, three $(20 \%)$ used a home computer, two (13\%) used youth club computers, and two (13\%) library computers. One (7\%) stated that he did not use the Internet.

With regard to information needs, employment needs were the most mentioned, followed by education, and then training to a much lesser degree. One participant $(7 \%)$ could not identify any information needs (note. same participant who did not use the Internet (retained as contributed to later questions)). Employment needs related to finding information on suitable job vacancies and preparation for interviews, including associated organisational details (addresses and contact details) and travel information (public transport timetables). Education needs related to finding information on FE courses, and completing coursework/exams. Training needs related to finding information on what training and apprenticeship opportunities are offered by partnerships agencies. Other information needs also mentioned related to finance (state benefit entitlements), health (pregnancy, contraception), and housing accommodation (council housing waiting lists).

With regard to information sources utilised, six participants (40\%) described scenarios were they sought and/or obtained information from partnership agency support workers (SDS, STEP, AtE), often identifying particular support workers. One participant described turning to a support worker for information about interviews because "they have more experience than anyone else I know". Another described turning to support workers for career advice because she felt they were "supportive". Another described finding out about his local youth club through his support worker who "just told me about it". Four participants (27\%) described turning to family and friends for information. One seeking to identify job vacancies she could apply for described turning to her mother and elder sister as she did this when she was "really stuck with something". Another seeking to identify an appropriate college course described turning to her husband because "He is the only person I can really talk to", who would then look for information and pass it on to her, but not always to her satisfaction as she described herself as "always asking more questions". Another described a friend telling him of a job that was available, but that when he made enquiries directly to the company "no one knew what I was talking about". Five participants (33\%) described scenarios combing multiple sources such as the Internet, family and friends, books and leaflets, and local youth clubs and health clinics. For example, one participant looking for information on FE courses described turning to the Internet because she "had a leaflet from the place but it didn't say much". Another described looking for information on contraception online because at the time that she was looking other sources such as her sexual health clinic and youth club were not open, but then obtaining leaflets from her sexual health clinic once open to gain "a second opinion". Another described attempting to find information about learning to drive (to increase employability) in books, but having difficulty with the terminology, so turning to his sister and father for help, as they both have driving licences.

With regard to difficulties, six participants $(40 \%)$ stated that they experienced no difficulties when looking for information, with a further four (27\%) declining to answer. Five participants (33\%) recounted difficulties and/or unmet needs. One described struggling to understand words in books, while another described difficulties with online searches and webpages that "take you from one page to the next" without providing the required information. Two described apprenticeship enquiries to Skills Development Scotland (SDS), one stating "Sometimes I don't feel like I get what I need... they don't see, what or how I am asking", and another stating, "They didn't give me any answers!". Another described making a housing enquiry (in person) to their local council, stating that, "[they] didn't give me what I needed", and described being sent somewhere else before "I... gave up".

Participants were asked if they used their local public library, with eleven (73\%) answering no. When asked why they did not use it, they variously answered that they were not interested or that there was nothing there for them. For example, one exclaimed "It's rubbish! Rubbish isn't the word l'd use but I don't want to say the other one here", while another asked if there even was a public library in the area (there are fourteen in South Ayrshire including one at each of the three sites of this study (and 
an additional mobile library service)). 'I don't read books' was a recurrent theme. Another participant, who was also a young mother, commented:

I used to (use the library) before I had my kids... the kids are just too loud. No one wants to listen to them go 'wah wah wah' all the time. It's a public library and everyone there... is so quiet.

Of the four participants $(27 \%)$ who did use their public library, one did so for fiction reading, two for computer access, and one to borrow DVDs; none considered themselves to be regular users or could recollect a recent visit.

\section{Focus group: young people}

Post interviews a focus group incorporating a participatory exercise was conducted. All volunteer participants were female (no males volunteered), and the average age was 16. Participants were asked to review and/or add to information sources identified from the interviews, and to then place them on a matrix according to perceived credibility (low-high) and frequency of use (low-high), and importantly, to discuss placements between themselves as they did so. The original intention of the focus group was to explore how participants discussed information behaviours as a group versus as individuals, and to further explore behaviours in the situational context; however, participants continued to demonstrate a reluctance to engage in lengthy discussions.

In addition to the previously identified information sources, participants' added the Job Centre, Skills Development Scotland My World of Work, newspapers, and television news. The category 'books and leaflets' was omitted by the group (considered too vague). The most credible sources were thought to be support workers, Job Centre, TV news, public transport companies, and Skills Development Scotland My World of Work. The Internet and the library were considered of medium credibility. The least credible resources were considered to be family and friends, and newspapers. The most frequently used information sources were identified as support workers, family and friends, the Internet, and television news. Newspapers, the Job Centre, and public transport companies were used with medium frequency. The least used resources were public libraries, and Skills Development Scotland My World of Work.

Participants provided brief commentary to accompany several of their placement decisions, with no notable disagreement or challenge between participants as they did so. Support workers were turned to because "they listen", and "usually have the answer" or "can find it", family and friends because "they're there" but "often don't know either". The Internet was "quick" but "sometimes confusing" and "too much". TV news was "on (in the home) all the time" and "because they show you what's really happening". Libraries were not used because "I don't like reading" and "I don't read much", and because "I'm not really good at reading". Participant placement of Job Centre, public transport companies, newspapers, and Skills Development Scotland's My World of Work involved no notable discussion beyond murmured agreement. Some researcher prompting for additional detail regarding the high credibility and low frequency of use ranking of Skills Development Scotland's My World of Work failed to solicit a response.

\section{Interviews: support workers}

Two support workers from Skills Development Scotland (SDS), two from South Ayrshire Councils Skills Towards Employment project (STEP) and two from Access to Employment (AtE) were interviewed.

With regard to information needs, support workers unanimously identified employment information as that which they provided most often, in particular relating to vacancies, apprenticeships, courses, and training opportunities; with the latter two dealt with least. In relation, one gatekeeper noted that young people, 'don't differentiate really between training and a job. They see if you are out on placement, like training, [...] if you are out every day getting paid that's a job'. Financial information was also identified as a key information need. Typical questions support workers dealt with centred on understanding entitlements (individual and family benefits) and how these might be impacted by changes in status such as leaving full-time education. In relation, young people often required 
assistance from support workers with identifying/confirming their personal bank account and national insurance details, and managing their day-to-day finances.

With regard to information sources utilised, support workers unanimously stated that they would not direct a young person to find information independently, but would instead guide them to recommended information sources, normally public and third sector partnership agencies. One support worker commented, "they really do want someone else to seek out the information, evaluate it and give them advice, like tell them what to do." Another discussed how young people often arrived misinformed through consulting friends first, commenting:

They want everything now, that's the other thing. So quite often they don't get the right information just because they haven't spent the time to find the right information, or their pals told them something that doesn't necessarily ring true to us.

Several support workers discussed a perceived preference for face-to-face information sources over online sources. One commented, "They like to recognise a face for the next time they come in". Another commented, "A lot of the time if you are trying to do stuff online they do feel a bit under pressure. They're happier going away with something in their hand". Another support worker suggested preferences were more evenly balanced, commenting:

There are some people who like doing everything on the Internet, and there are other people who are frightened of it and they just want to be told. So I would say [preferences are] sort of $50 / 50$.

Support workers identified a number of barriers to information seeking amongst young people: isolation, institutional problems, literacy issues, home life, motivation, and social skills.

Isolation was raised by several support workers, one commenting that "location can be [a barrier], especially in places like Girvan", while another stated "a barrier I still think in using information is that they are still quite isolated in where they stay". Another commented that, "many don't actually look for information... in Girvan especially they are insulated, and can't see opportunities outside of their own worlds".

Institutional problems, in particular stringent policies and inflexible attitudes, were also identified as a difficult barrier to overcome, one support worker commenting:

The most difficult barriers happen when there are two priorities pulling the person in different directions. With the job centre crossover there is a lot going against you. My organisation is very person centred... some places are more rules and regulations focused which makes things difficult.

The majority of support workers raised literacy issues. One commented that, "they can go on to play a computer game or go on to Facebook but they don't actually have the skills to get in to these sorts of [information] areas". Another stated:

A lot of them don't have access to the Internet at home, or wherever they are living. And even having the ability to use computers to do that, I would say is a huge... [barrier] for a young person who is not using IT for that kind of thing on a daily basis.

One support worker discussed how a lack of online skills could lead to benefit sanctions, commenting:

I've noticed... a lot more of my caseload's benefits being sanctioned by the job centre because they're not doing the [online] universal job match. And basically, a lot of them, it's because they don't know how to use it.

Several support workers identified a lack of confidence as a significant barrier to NEET youth seeking information themselves. Support workers would consequently help NEET youth find information, but would often find themselves obtaining rather than assisting, a situation considered unsatisfactory on reflection. For example, one support worker stated "...probably we would just find the information for them on the Internet, but we could do that jointly". 
Home life was also considered a barrier, and in relation, familial unemployment. One support worker commented that "second and third generation unemployment, becoming conditional... people believe that's all there is". Another commented:

Sometimes the barrier is when the parents just give them everything... So that they don't do anything for themselves and they don't expect to have to do anything for themselves and that's even harder. And they're getting given money... So they have no motivation.

Lack of motivation was a recurrent theme attributed by support workers to issues such as familial unemployment, and also to substance abuse, with one support worker commenting "drug and alcohol issues, because of their use of that, they don't have the motivation". The issue of attention span was also raised, one support worker commenting that "they often don't have the patience to sit down and read and assimilate... information". The same support worker stated that many of the young people she works with have literacy issues, alcohol and drug problems, and that much of what she does is "helping them with social skills".

\section{Discussion}

Online activities of NEET youth appear similar to general population peers with general browsing, social networking, and music and gaming commonly cited as popular activities; however, many of our participants spent notably more time online than their peer group average of 24.2 hours per week (e.g. Ofcom, 2014a; 2014b). 40\% of our participants spent upwards of 42 hours per week online, and a further $20 \%$ between $21-42$ hours per week, potentially attributable to increased free time.

The most important information needs identified by NEET youth were employment related, followed by education and training. However, our participants also expressed information needs related to finance, health, and housing, with several notably unmet and with implications for their general health and wellbeing. Further 'everyday' studies appear warranted.

In terms of information sources utilized by NEET youth, support workers are used with high frequency and considered of high credibility, as is television news. The Internet is used with high frequency and considered to be of medium credibility. Family and friends are used with high frequency and considered of low credibility. Job Centre's are used with medium frequency, and considered of high credibility, as are public transport companies. Newspapers are used with medium frequency and considered to be of low credibility. The SDS World of Work careers website is used with low frequency and considered of high credibility. Public libraries are used with low frequency and considered to be of medium credibility.

A preference for people (face to face) as information sources aligns with the previous findings such as those of Agosto and Hughes-Hassell (2006), who in a study of the everyday life information needs of urban teenagers aged 14-17, report preferences for family and friends over teachers, careers advisors, and librarians; with choice of information source determined by subject of query, strength of relationship, and proximity. It is interesting to note that in this study support workers appeared to be used as frequently as family and friends, and were considered a more credible source of information. A degree of trust in support workers is also suggested by NEET youth comments that support workers are "supportive" and "...listen" and suggests that in disadvantaged circumstances, support workers are important members of social networks.

Evidence of bonding social capital was found in NEET youth connections to immediate family and friends, who were used frequently as information sources (notwithstanding issues of credibility). Evidence of bridging social capital was limited to support worker efforts who were actively directing many NEET youth to local voluntary groups, youth clubs, sports clubs, and recreational community projects due to concerns about isolation and a lack of social skills amongst NEET youth; however, only two of our participants mentioned such groups, with participation unclear. In fact, it is notable that we found no evidence whatsoever suggesting any of our participants actively participated in youth groups or clubs. A degree of linking social capital was also evident in support worker efforts to facilitate cross-institutional access and support; however, again there was no evidence to suggest connections were being formed. In relation, it is noteworthy that of the five instances of difficulties recounted by NEET youth, three were related to seeking information from other institutions with 
subjects stating, “Sometimes I don't feel like I get what I need... they don't see, what or how I am asking", "They didn't give me any answers, and "[they] didn't give me what I needed".

Our findings suggest that the social capital of NEET youth is largely limited to bonding social capital characteristically exclusive and inward facing, as opposed to more open and outward facing bridging and linking social capital (Putman, 2000; Woolcock, 2000). Support worker concerns regarding isolation appear to support this conclusion, as does our understanding of issues of low self-esteem and confidence, also known to increase the risk of social exclusion (e.g. Kieselback, 2003). Such findings align with Chatman's (1996) concepts of situational relevance and risk taking, and suggest a reliance on localised information sources.

The majority of NEET youth exhibited non-motivated and passive information behaviours, and a dependency upon support workers when seeking and processing information. However, interactions between NEET youth and support workers could nonetheless be protracted and unproductive, with many subjects withdrawn, and appearing unable or reluctant to articulate or discuss their needs. Such behavioural issues are not exclusive to NEET youth, for we know that adolescents in general are at a stage in their psychological development when they prioritise independence and are less receptive to information channels which they perceive to make them dependent on others (Coleman, 2010). Young people of NEET status are just as likely (as their general population peers) to reject information sources that cause them to feel dependent, potentially more so when compounded by issues of low self confidence and stigma (stigma being associated with NEET status (Yates \& Payne, 2006), and stigma known to influence information practices (Lingel \& Boyd, 2013)). Such behaviours align with Chatman's (1996) concepts of risk taking and secrecy, and issues of mistrust and concealment. Behaviours also contrast with the findings of Foss et al (2013) who report a decrease in non-motivated behaviours and an absence of distracted behaviours amongst general population adolescents not evident here.

Six participants $(40 \%)$ stated that they experienced no difficulties when looking for information, with a further four (27\%) declining to comment. Five participants (33\%) recounted difficulties variously attributed to literacy issues, difficulties in articulating information needs, and unmet information needs. That barriers were not identified or recounted by two thirds of participants is significant, and questionable. In related studies examining adolescent career/employment related information, and involving participants who might be expected to experience less barriers, the number of participants who recounted experiencing barriers was higher, ranging from 55\% (Webber and Zhu, 2007) to $70 \%$ (Julian, 1999). During observation we observed the majority of NEET youth experiencing difficulties with information processing tasks (many abandoned) and exhibiting a wide range of unmet information needs. Support worker comments reinforced our observations, and added to identified barriers: home life, isolation, institutional problems, literacy and access issues, motivation, and social skills. A possible explanation for our participant responses to this question is provided by Chatman (1996, p.197), who argues that when hindered from seeking information "...we engage in selfprotective behaviours to keep others from sensing our need. These behaviours are meant to hide our true crisis in an effort to appear normal and to exhibit acceptable coping behaviours". Triangulation of data suggests secrecy amongst those participants who declined to comment, and deception amongst those who stated that they experienced no difficulties; again aligning with two of Chatman's (1996) key concepts.

Significant literacy issues (encompassing reading, computer, and information) are evident, exemplified by repeat observations of young people struggling with online searches, setting up accounts and completing forms, and processing information, and showing reluctance to take part in activities involving reading. Notably, the majority of the support workers stated that they would not direct a young person to find information independently, but would instead guide them to information sources. In relation, there was no evidence of proactive transitions to independent information seeking from either party, nor of basic literacy issues being explicitly addressed (although arguably falling out with the direct remit (and primary skills) of support workers). Remedial education appears warranted for both immediate and long term needs (supporting OECD (2014b) calls). In such circumstances public libraries (PL) could provide a key access and support role, but it is evident that NEET youth do not use PLs, the majority having narrow views of PL services, and some possessing quite extreme negative opinions. Such findings align with previous studies of general population adolescents (e.g. Agosto and Hughes-Hassell, 2005; Julien, 1999), and for our subjects, also with Chatman's (1996) concept of situational relevance and proposition that an individual living in an 
impoverished state will fail to see external information sources as of direct and immediate value to lived experiences. Such findings suggest that a rethink is needed in how PLs meet the needs of adolescents, particularly in disadvantaged and disengaged circumstances. We suggest that a more proactive outreach approach is needed that sensitively addresses issues of confidence and selfefficacy (and perceptions of independence). Such efforts might assist with addressing issues of motivation by reducing a significant (literacy) barrier to personal empowerment, increasing selfconfidence, and in turn, self-efficacy. Further action-oriented interdisciplinary research appears warranted to support such activity that importantly, focuses on influencing information behaviours.

\section{Conclusion}

Our interdisciplinary theoretical framework brought together theories of information poverty with theories of social capital to better understand adolescent information behaviours in disadvantaged and disengaged circumstances, and explore issues of social integration. Our findings suggest that NEET youth face heightened access and internalised behavioural barriers beyond those common to the general adolescent population, the former influenced by technology and literacy issues, the latter by social structures and norms. There is evidence suggestive of deception, risk-taking, secrecy, and situational relevance in their (often self protective) information behaviors, and a reliance on bonding social capital characteristically exclusive and inward facing. All are indicative of an impoverished information world.

Low levels of literacy and self-efficacy are significant interrelated issues, with NEET youth demonstrating passive non-motivated information behaviours, often abandoned; and a dependency upon support workers when seeking and processing information. Remedial literacy education (reading, computer, and information) should be an immediate priority for public and third sector agencies, addressing both immediate and long-term needs. Librarian collaboration and interventions appears warranted, with tailored outreach provision recommended that seeks to build sustained relationships over the short to medium term (tailored provision and sustained relationships being two of four common features of successful intervention programmes, the other two being incentives and recreational activities (Audit Commission, 2010). Such efforts might assist with addressing issues of motivation by reducing a significant barrier to personal empowerment, increasing self-confidence, and in turn, self-efficacy. Such interventions face a number of significant challenges, not least managing adolescent perceptions of independence in dependent and vulnerable situations, and issues of trust.

Our findings evidence and draw attention to understudied and enduring information poverty issues of significant societal concern potentially consigning a significant proportion of the global youth population $(954,000$ in the UK alone (Office for National Statistics, 2014) to a stratified and disengaged existence within an impoverished (small) information world. Further interdisciplinary research studies are recommended as an immediate priority to explore complex relations between social and affective factors, and that seek to both understand and influence information behaviours in disadvantaged and disengaged circumstances. An action oriented research approach appears warranted to balance the needs for further understanding with the needs for immediate intervention. 
Agosto, D. E., \& Hughes-Hassell, S. (2005). People, places, and questions: An investigation of the everyday life information-seeking behaviors of urban young adults. Library \& information science research, 27(2), 141-163.

Agosto, D. E., \& Hughes-Hassell, S. (2006a). Toward a model of the everyday life information needs of urban teenagers, part 1: Theoretical model. Journal of the American Society for Information Science and Technology, 57(10), 1394-1403.

Agosto, D. E., \& Hughes-Hassell, S. (2006b). Toward a model of the everyday life information needs of urban teenagers, part 2: Empirical model. Journal of the American Society for Information Science and Technology, 57(11), 1418-1426.

Agosto, D. E., Abbas, J., \& Naughton, R. (2012). Relationships and social rules: Teens' social network and other ICT selection practices. Journal of the American Society for Information Science and Technology, 63(6), 1108-1124.

Audit Commision (2010). Against the Odds: reengaging young people in education, employment or training. Available at: http://www.audit-commission.gov.uk/2010/07/against-the-odds-re-engagingyoung-people-in-education-employment-or-training/

Bowler, L. (2010). The self regulation of curiosity and interest during the information search process of adolescent students. Journal of the American Society for Information Science and Technology, 61(7), 1332-1344.

Bowler, L., Hong, W. Y., \& He, D. (2011). The visibility of health web portals for teens. Online Information Review, 35(3), 443-470.

Braun, V., \& Clarke, V. (2006). Using thematic analysis in psychology. Qualitative research in psychology, 3(2), 77-101.

Britz, J. (2004) To know or not to know: a moral reflection on information poverty. Journal of Information Science, 30(3), 192-204.

Bryman, A. (2012). Social research methods. Oxford university press.

Chatman, E. A. (1996). The impoverished life-world of outsiders. Journal of the American Society for Information Science, 47(3), 193-206.

Chung, J.S., and Neuman, D. (2007) High school students' information seeking and use for class projects. Journal of the American Society for Information Science and Technology, 58(10), 15031517.

Coleman, J. (2010) The nature of adolescence, $4^{\text {th }}$ ed., Routledge.

Dietrich, H. (2012). Youth unemployment in Europe: theoretical considerations and empirical findings. Available at: http://library.fes.de/pdf-files/id/ipa/09227.pdf

Drentea, P., \& Moren-Cross, J. L. (2005). Social capital and social support on the web: the case of an internet mother site. Sociology of health \& illness, 27(7), 920-943.

Foss, E., Druin, A., Yip, J., Ford, W., Golub, E., \& Hutchinson, H. (2013). Adolescent search roles. Journal of the American Society for Information Science and Technology, 64(1), 173-189.

Franzèn, E. M., \& Kassman, A. (2005). Longer-term labour-market consequences of economic inactivity during young adulthood: a Swedish national cohort study. Journal of Youth Studies, 8(4), 403-424.

Gentry, J., \& Campbell, M. (2002). Developing adolescents: a reference for professionals. Washington, DC: American Psychological Association.

Gilbert, N. (Ed.). (2008). Researching social life. Sage.

Goulding, A. (2004). Editorial Libraries and Social Capital. Journal of Librarianship and Information Science, 36(1), 3-6.

Guest, G., Bunce, A., \& Johnson, L. (2006). How many interviews are enough? An experiment with data saturation and variability. Field methods, 18(1), 59-82.

Haider, J., \& Bawden, D. (2007). Conceptions of "information poverty" in LIS: a discourse analysis. Journal of Documentation, 63(4), 534-557. 
Hammer, T. (2003). The probability for unemployed young people to re-enter education or employment: A comparative study in six northern European countries. British Journal of Sociology of Education, 24(2), 209-223.

Harris, F.J. (2008) Challenges to teaching credibility assessment in contemporary schooling. In Metzger, M.J., and Flanagin, A.J. (Eds.), Digital Media, Youth, and Credibility, 155-180. Cambridge: MIT Press.

Howard, V. (2011). The importance of pleasure reading in the lives of young teens: Self-identification, self-construction and self-awareness. Journal of Librarianship and Information Science, 43(1), 46-55.

International Labour Organisation (2014). Global Employment Trends 2014: The risk of a jobless recovery. Available at: http://www.ilo.org/global/research/global-reports/global-employmenttrends/2014/WCMS 233953/lang--en/index.htm

International Labour Organisation (2015) World Employment Social Outlook. Available at: http://www.ilo.org/global/research/global-reports/weso/2015/WCMS 337069/lang--en/index.htm

Jackson, M., and Banwell, L. (2005) Mind the gaps: 'A' level students and IL. Library and Information Update, 4(1/2), 42-43.

Johnson, C. A. (2004). Choosing people: the role of social capital in information seeking behaviour. Information Research, 10(1), 10-1.

Julien, H. E. (1999). Barriers to adolescents' information seeking for career decision making. Journal of the American Society for Information Science, 50(1), 38-48.

Kieselbach, T. (2003). Long-term unemployment among young people: the risk of social exclusion. American journal of community psychology, 32(1-2), 69-76.

Kim, S. U., \& Syn, S. Y. (2014). Research trends in teens' health information behaviour: a review of the literature. Health Information \& Libraries Journal, 31(1), 4-19.

Lanning, T., \& Rudiger, K. (2012). Youth unemployment in Europe: lessons for the UK. Available at: http://www.researchonline.org.uk/sds/search/download.do;jsessionid=8EB0BC2ACB09A1B9DD9ED6 AA24C78047?ref=B27130

Lingel, J., \& Boyd. D. (2013) "Keep it secret, keep it safe": Information poverty, information norms, and stigma. Journal of the American Society for Information Science and Technology, 64(5), 981-991.

Merton, R.K. (1972) Insiders and outsiders: A chapter in the sociology of knowledge. American Journal of Sociology, 78, 9-47.MLA, DCMS, and Laser Foundation (2006) A Research Study of 14-35 year olds for the Future Development of Public Libraries. Available at: http://research.mla.gov.uk/evidence/view-publication.php?dm=nrm\&pubid=139

Miles, M., \& Huberman, A.. (1994). Qualitative data analysis: An expanded sourcebook. Sage.

Miller, J., McAuliffe, L., Riaz, N., \& Deuchar, R. (2015). Exploring youth's perceptions of the hidden practice of youth work in increasing social capital with young people considered NEET in Scotland. Journal of Youth Studies, (ahead-of-print), 1-17.

Nicholas, D., Rowlands, I., Clark, D., \& Williams, P. (2011). Google Generation II: web behaviour experiments with the BBC. In Aslib Proceedings (Vol. 63, No. 1, pp. 28-45). Emerald Group Publishing Limited.

O'Dea, B., Glozier, N., Purcell, R., McGorry, P. D., Scott, J., Feilds, K. L., \& Hickie, I. B. (2014). A cross-sectional exploration of the clinical characteristics of disengaged (NEET) young people in primary mental healthcare. BMJ open, 4(12), e006378.

OECD (2014a) Society at a Glance 2014. Available at: http://www.oecd-ilibrary.org/social-issuesmigration-health/society-at-a-glance-2014 soc glance-2014-en

OECD (2014b) OECD Employment Outlook 2014. Available at: http://www.oecdilibrary.org/employment/oecd-employment-outlook-2014/summary/english 45c7c585-en

Ofcom (2014a) Internet use and attitudes: 2014 Metrics Bulletin. Available at: http://stakeholders.ofcom.org.uk/market-data-research/other/internet/internet-use-and-attitudesbulletin/ 
Ofcom (2014b) Adults' Media Use and Attitudes Report. Available at:

http://stakeholders.ofcom.org.uk/market-data-research/other/research-publications/adults/adultsmedia-lit-14/

Ofcom (2014c) Children and Parents: Media Use and Attitudes Report. Available at:

http://stakeholders.ofcom.org.uk/binaries/research/media-literacy/media-use-attitudes-

14/Childrens_2014_Report.pdf

Office for National Statistics (November 2014). Statistical Bulletin: Young People Not in Education, Employment or Training November 2014. Available at: http://www.ons.gov.uk/ons/rel//ms/youngpeople-not-in-education--employment-or-training--neets-/november-2014/stb---young-people-not-ineducation--employment--training--neet----november-2014.html

Pickard, A. (2004) Young people and the internet. Library and Information Update, 3(1), 32-34.

Princes Trust (2013) Digital Literacy Survey. Available at: http://www.princes-

trust.org.uk/about_the_trust/what_we_do/research/digital_literacy_research_2013.aspx

Princes Trust (2014). The Princes Trust MacQuarie Youth Index 2014. Available at:

http://www.princes-trust.org.uk/about the trust/what we do/research/youth index 2014.aspx

Putnam, Robert (2000) Bowling Alone: The Collapse and Revival of American Community. New York: Simon and Schuster.

Reading Agency. (2004) Fulfilling their potential: a national development programme for young people's library services. Available at: http://readingagency.org.uk/young/young\%20peopleupload/FPsummaryreport04.pdf

Reading Agency. (2011) Libraries and digital: research into the use of digital media in libraries to develop audiences for reading. Available at: http:// www.readingagency.org.uk/

Rideout, V. (2002). Generation Rx. com. what are young people really doing online?.Marketing Health Services, 22(1), 26.

Rowlands, I., Nicholas, D., Williams, P., Huntington, P., Fieldhouse, M., Gunter, B., \& Tenopir, C. (2008, July). The Google generation: the information behaviour of the researcher of the future. Aslib Proceedings, 60 (4), 290-310).

Sánchez-Navarro, J., \& Aranda, D. (2013). Messenger and social network sites as tools for sociability, leisure and informal learning for Spanish young people. European Journal of Communication, 28(1), 67-75.

Scottish Index of Multiple Deprivation (2012) Local Summaries SIMD 2012. Available at: http://simd.scotland.gov.uk/publication-2012/local-authority-summaries-simd-2012/

Shenton, A.K., and Dixon, P. (2004) Issues arising from youngsters' information-seeking behavior. Library \& Information Science Research 26(2), 177-200.

Schuller T., Baron, S., Field, J. (2000) Social capital: A review of critique. In: Social Capital: Critical Perspectives, edited by S. Baron, J. Field and T. Schuller, Oxford, pp.1-38, Oxford University Press.

SPICe (2012) Youth unemployment: key facts. Available at: http://www.scottish.parliament.uk/ResearchBriefingsAndFactsheets/S4/SB 12-19rev.pdf

Stoten, D.W. (2014). NEETs: a case study in addressing the issues relating to disengaged youth in East Cleveland. Education+ Training, 56(5), 467-480.

United States Department of Labor (2014) Employment Situation October 2014. Available at: http://www.bls.gov/bls/newsrels.htm

Wanberg, C. R. (2012). The individual experience of unemployment. Annual review of psychology, 63, 369-396.

Welsh Government Social Research. (2013) Identifying Young People at Risk of becoming 'Not in Employment, Education and Training. Available at: http://new.wales.gov.uk/statistics-andresearch/identifying-young-people-risk-becoming-not-education-employment-training/?lang=en

Woolcock, M., \& Narayan, D. (2000). Social capital: Implications for development theory, research, and policy. The world bank research observer, 15(2), 225-249. 
Williamson, K., Qayyum, A., Hider, P., \& Liu, Y. H. (2012). Young adults and everyday-life information: The role of news media. Library \& Information Science Research, 34(4), 258-264.

Webber, S., \& Zhu, W. (2007). Employment information needs of Chinese young adults in Sheffield. Journal of Librarianship and Information Science, 39(4), 223-233.

Yates, S., \& Payne, M. (2006). Not so NEET? A critique of the use of 'NEET' in setting targets for interventions with young people. Journal of Youth Studies, 9(3), 329-344. 